\title{
A Procurement Auction for Toxic Assets with Asymmetric Information
}

\author{
By Olivier Armantier, Charles A. Holt, and Charles R. Plott*
}

\begin{abstract}
The proposed 2008 TARP auction was intended to remove "toxic" assets from portfolios of financially stressed banks. The Treasury selected a design whereby bids to sell different securities would be normalized by "reference prices" that reflect relative value estimates. We conduct a series of experiments indicating that a simple Reference Price Auction can be an effective mechanism for avoiding serious effects of adverse selection and strategic bid manipulation, even with inaccurate reference prices. Beyond the TARP auction, our results are relevant to various multi-object auctions with value heterogeneity. (JEL D44, D82, G21)
\end{abstract}

I

n the fall of 2008, as the financial crisis reached a critical stage, the US Treasury was setting up a series of auctions to purchase potentially thousands of highly heterogeneous mortgage-backed securities (MBS) from financial institutions as part of the TARP (Troubled Assets Relief Program). With a budget of up to $\$ 700$ billion, this would have been the largest auction in history, surpassing even the largest spectrum auctions by a factor of ten (Binmore and Klemperer 2002). Since no appropriate "off-the-shelf" design existed for this purpose, a new auction format had to be rapidly developed. The scale of the proposed auction and the immediacy of the crisis generated considerable discussion among economists (e.g., Varian 2008; Brusco 2008; Ausubel and Cramton 2008). ${ }^{1}$ After consulting with academic experts,

\footnotetext{
*Armantier: Federal Reserve Bank of New York, 33 Liberty Street, New York, NY 10045 (e-mail: olast1@ gmail.com); Holt: Department of Economics, PO Box 400182, University of Virginia, Charlottesville, VA 22904 (e-mail: holt@virginia.edu); Plott: Division of the Humanities and Social Sciences, 228-77 California Institute of Technology, Pasadena, CA 91125 (e-mail: cplott@hss.caltech.edu). We wish to thank Claudia Antonacci, Andrew Barr, Rachel Blank, Anne Dragnova, Sara St. Hilaire, Stephanie Lawrence, Courtney Mallow, Karl Schurter, and Sean Sullivan for research assistance. We also thank seminar and conference participants at the 2009 Workshop on Neuroeconomics and Psychology in Toulouse, the 2009 Public Economic Conference in Lyon, the 2009 ESA meeting in Tucson, the 2010 ESA meeting in Melbourne, the University of Technology in Sydney, and the LeeX International Conference on Theoretical and Experimental Macroeconomics. We are grateful to Jamie McAndrews and Kenneth Garbade for helpful comments. This research was supported in part by the University of Virginia Bankard Fund for Political Economy, and by the CIRANO lab in Montréal, where some of the experiment sessions were conducted. Along with Treasury staff, other Federal Reserve employees, and other auction experts from academia, the authors were part of the team set up by the US Treasury in the fall of 2008 that designed an auction to purchase mortgage related assets. The views expressed here are those of the authors and do not reflect the views of the US Treasury or the views of other members of that "Treasury team." Likewise, the views expressed here do not necessarily reflect the views of the Federal Reserve Bank of New York or the Federal Reserve System.

${ }^{\dagger}$ Go to http://dx.doi.org/10.1257/mic.5.4.142 to visit the article page for additional materials and author disclosure statement(s).

${ }^{1}$ Numerous economists also questioned the appropriateness of purchasing illiquid MBS. See, e.g., the open letter signed by more than 100 economists sent to Congress on September 24, 2008 (http://faculty.chicagobooth.edu/ john.cochrane/research/Papers/mortgage_protest.htm).
} 
the Treasury selected a new design, a "Reference Price" auction. It was unclear, however, how this design would perform. In this paper, we report on an experiment aimed at testing different features of the Reference Price Auction adopted by the Treasury. Beyond the TARP, the lessons learned in this exercise apply to a broad set of similar multi-object auctions.

The Reference Price design the Treasury selected is a version of what is known in the literature as a "scoring auction," in which bids with heterogeneous characteristics are homogenized through the use of a score that incorporates both price and nonprice dimensions of the bids (e.g., quality). ${ }^{2}$ As further explained in Section I, the nonprice dimension for the TARP auction was to be based on "reference price" estimates of the relative values of the MBS (Swagel 2009). It was believed that the main benefit of this design is that it could promote competition and provide some protection against adverse selection. In addition, although undoubtedly suboptimal in the formal mechanism design sense, it was deemed simple, transparent, and robust enough to be implemented rapidly and effectively to purchase thousands of different securities. The Treasury team in charge of designing the auction, however, realized that the performance of the design may rely heavily on its ability to precisely estimate reference prices. As such, an exercise could not be conducted without making mistakes, and concerns were expressed about the possibility that bidders could exploit these mistakes at the Treasury's expense. Several remedies were proposed to mitigate this problem. In particular, it was suggested that the Treasury would only reveal reference prices after the auction, so that the bidders would not be able to observe the Treasury's valuation errors at the time bids are submitted.

Given the complexity of the environment and the time constraints, it appeared difficult to address the relevant issues directly with economic theory. A commonly used procedure in such situations is to conduct laboratory experiments that simulate the environment with financially motivated human subjects. ${ }^{3}$ The objective of the experiment conducted in this paper is threefold. First, we want to test whether a Reference Price Auction with accurate reference prices performs better (from the buyer's perspective) than a Grand Auction in which all securities are pooled together in a single reverse auction and purchased at a single price irrespective of the security accepted. Second, we want to explore how sensitive the Reference Price Auction is to reference prices that are incorrectly set by the buyer. More specifically, we want to test whether announcing noisy (instead of accurate) reference prices before the auction generates inefficiencies, as bidders can exploit mistakes made by the buyer. Third, we want to test one of the measures proposed to protect the Treasury against setting incorrect reference prices. Namely, we test whether the Reference Price Auction performs better for the buyer when the noisy reference prices are kept secret at the time of bidding.

Although this study was motivated by the TARP auction, our results are relevant more broadly to similar multi-object auctions. In addition to the scoring auctions

\footnotetext{
${ }^{2}$ See Armantier, Florens, and Richard (1998); Armantier (1999); Stoneham et al. (2002); Cason, Gangadharan, and Duke (2003); or Asker and Cantillon (2008) for other forms of scoring auctions.

${ }^{3}$ See Plott (2001) and Holt, Shobe, and Smith (2007) for surveys on the use of laboratory experiments to guide public policy initiatives, including auctions. For specific examples of auction designs that have been tested in the lab before being implemented in the field, see Holt et al. (2008); Goeree and Holt (2010); or Cummings, Holt, and Laury (2004).
} 
discussed in the papers mentioned in footnote 2 , there are several examples within the realm of finance in which various items with heterogeneous characteristics are auctioned simultaneously. This is the case when a financial institution attempts to raise a certain amount of liquidity by auctioning the various assets of a failing institution, or a large portfolio of mortgage-backed securities with different characteristics (e.g., rating, vintage). ${ }^{4}$ Another important example is the case of Open Market Operations in which a central bank decides to purchase for a fixed dollar amount of various securities from a set of eligible sellers. The challenge for a central bank is to compare the prices submitted for different securities in order to decide which bids to accept. In the United States, the Federal Reserve addresses this challenge with a variant of the Reference Price Auction described in this paper. ${ }^{5}$

The remainder of the paper is structured as follows. The Reference Price Auction is explained in Section I. Section II details the experimental procedures used to compare parallel series of laboratory test auctions. Section III summarizes the main results of these experiments in terms of purchase efficiency (defined as the value of securities purchased relative to total expenditure) and price discovery (auction clearing prices relative to unobserved security values). In Section IV, we conduct an econometric analysis to better understand differences in bidding behavior and auction outcomes.

\section{The Reference Price Auction}

In this section, we present the basic principles underlying the Reference Price Auction. To convey the intuition behind these principles and to contrast the Reference Price Auction with the Grand Auction, we consider a simple example with two bidders and two securities. Bidder 1 owns one unit of security A, while bidder 2 owns two units of security B. As indicated in Table 1, the low quality security A has a value of 5 , while the high quality security B has a value of ten. To simplify, we assume that the values of the two securities are known to the bidders but not to the auctioneer. The bidders therefore compete in a complete information environment. Consistent with the design adopted by the Treasury for the TARP program, we consider a reverse auction with sealed bids, and with a uniform price mechanism (i.e., the lowest bids win and are paid the lowest rejected bid). ${ }^{6}$ For each unit they own, participants can submit a bid price. Bids are constrained to be integers and ties are decided at random. Finally, the government budget is assumed to be 18 .

Consider first the Grand Auction in the top panel of Table 1. As explained below, this is a special case of Reference Price Auction in which all reference prices are set to one. It is easy to verify that value bidding is an equilibrium in this Grand Auction.

\footnotetext{
${ }^{4}$ These two cases correspond to single-seller auctions, not procurement auctions like the TARP. From a theoretic perspective, however, the two mechanisms may be considered equivalent.

${ }^{5}$ Additional examples include the cash auctions conducted by the Bank of England (Klemperer 2010), and two-sided markets for bonds where preset reference prices are used to homogenize bonds of different maturities (Hasbrouck 2007).

${ }^{6}$ See the supplemental materials for a discussion of the design choices for the TARP auction.
} 
TABle 1 -EXAMPLE UNDER COMPLETE INFORMATION

(Value of security $A=5$, value of security $B=10$, government budget $=18$ )

\begin{tabular}{|c|c|c|c|c|c|c|c|c|}
\hline & & \multirow{2}{*}{$\begin{array}{c}\text { Bidder } 1 \\
\text { Security A } \\
V=5\end{array}$} & \multicolumn{2}{|c|}{ Bidder 2} & \multirow[b]{2}{*}{$\begin{array}{l}\text { Security } \\
\text { purchased }\end{array}$} & \multirow[b]{2}{*}{$\begin{array}{l}\text { Price } \\
\text { paid }\end{array}$} & \multirow[b]{2}{*}{$\begin{array}{l}\text { Value } \\
\text { purchased }\end{array}$} & \multirow[b]{2}{*}{$\begin{array}{l}\text { Purchase } \\
\text { efficiency }^{\dagger}\end{array}$} \\
\hline & & & $\begin{array}{l}\text { Security B } \\
V=10\end{array}$ & $\begin{array}{c}\text { Security B } \\
V=10\end{array}$ & & & & \\
\hline $\begin{array}{c}\text { Grand Auction } \\
\text { (reference prices: } 1 \text { for } \mathrm{A} \text { and } \mathrm{l} \text { for } \mathrm{B} \text { ) }\end{array}$ & $\begin{array}{c}\text { Bid } \\
\text { Normalized bid } \\
\text { Bidder's profit }\end{array}$ & $\begin{array}{l}5 \checkmark \\
5 \\
5\end{array}$ & $\begin{array}{l}10 \\
10 *\end{array}$ & $\begin{array}{l}10 \\
10 *\end{array}$ & A & 10 & 5 & $1 / 2$ \\
\hline $\begin{array}{c}\text { Known accurate } \\
\text { reference price } \\
\text { (reference prices: } 1 \text { for } \mathrm{A} \text { and } 2 \text { for } \mathrm{B} \text { ) }\end{array}$ & $\begin{array}{c}\text { Bid } \\
\text { Normalized bid } \\
\text { Bidder's profit }\end{array}$ & $\begin{array}{l}5 \checkmark \\
5 \\
1\end{array}$ & $\begin{array}{c}12 \checkmark \\
6\end{array}$ & $\begin{array}{l}12 \\
6^{*}\end{array}$ & $\mathrm{~A}$ and $\mathrm{B}$ & $6+12$ & $5+10$ & $5 / 6$ \\
\hline $\begin{array}{l}\text { Known overpriced } \\
\text { reference price } \\
\text { (reference prices: } 1 \text { for } \mathrm{A} \text { and } 3 \text { for } \mathrm{B} \text { ) }\end{array}$ & $\begin{array}{c}\text { Bid } \\
\text { Normalized bid } \\
\text { Bidder's profit }\end{array}$ & $\begin{array}{l}5 \\
5^{*} \\
0\end{array}$ & $\begin{array}{c}15 \\
5^{*}\end{array}$ & $\begin{array}{c}12 \checkmark \\
4\end{array}$ & B & 15 & 10 & $2 / 3$ \\
\hline
\end{tabular}

${ }^{\dagger}$ Purchase efficiency is the ratio of the value purchased to the government expenditure.

* Indicates the lowest rejected bid.

$\checkmark$ Indicates a bid accepted by the auctioneer.

Thus, the auctioneer accepts bidder 1's offer on the low quality security (with a check mark in column 3) and pays a clearing price equal to ten, the value of the high quality security (as indicated by an asterisk in the normalized bid row). With a budget of 18 , the auctioneer cannot afford a unit of security B since it would cost an additional ten. Bidder 1 then makes a profit of 5, while the auctioneer's purchase efficiency, defined as the value of all the securities purchased relative to the auctioneer's total expenditure, is equal to $1 / 2$ (see the last column of Table 1). ${ }^{7}$ The Grand Auction therefore exhibits severe adverse selection since the auctioneer purchases the low quality security A (which is not a problem per se), but overpays considerably by spending an amount equal to the value of the high quality security $\mathrm{B} .{ }^{8}$

Consider now the Reference Price Auction. One of the basic principles underlying this design is that the auctioneer sets "reference prices" so as to reflect estimates of the values of the various securities relative to a baseline security. ${ }^{9}$ Let us consider first the case where the auctioneer accurately assesses these relative values and announces them before the auction. In that case, security B would be assigned a reference price of 2 in our example since it is twice as valuable as the baseline security A (see the middle panel of Table 1). Each bid is then normalized by dividing the unit price bid by the reference price corresponding to that security. As a result, the bids for different securities are homogenized and can be compared. In the example in Table 1 for instance, the bids on security B are divided by their reference price of two in order to make them comparable to bids on the baseline security. The normalization process therefore lowers (respectively, raises) the price bid for securities with higher values (respectively, lower values).

\footnotetext{
${ }^{7}$ It is also an equilibrium for bidder 2 to submit a per-unit bid anywhere between 10 and 18 , in which case the auctioneer would spend more than 10 for the unit of security A. Therefore, purchase efficiency in this Grand Auction can be anywhere between $5 / 18$ (or about 0.28 ) and $1 / 2$.

${ }^{8}$ A security-by-security auction would effectively deal with the unobserved value heterogeneity. As discussed in the supplemental materials, this approach was considered impractical and undesirable for the TARP.

${ }^{9}$ For the TARP, these reference prices would have been calculated by combining the latest transactions data, other market information (e.g., Markit ABX index, the subprime residential MBS credit derivative), valuation models, expert opinions, and prices from previous TARP auctions.
} 
The bids with the lowest normalized bids are accepted first, moving up the list until the auctioneer's budget is exhausted. Under a uniform price auction, all winning bidders for a given security would receive the same price per unit. To determine this price, the "market clearing normalized price" (i.e., the lowest rejected normalized price bid) must first be calculated. This common cutoff normalized price, multiplied by the corresponding reference price, determines the "market clearing price" per unit for a given security.

To illustrate, consider our example with accurate reference prices in the middle panel of Table 1 . It is easy to verify that by bidding above value, bidder 2 can manage to sell one unit of security B in equilibrium. As indicated in Table 1, bids of 12 per-unit by bidder 2 produce normalized bids of 6 , in which case the market clearing normalized price is also 6 . The auctioneer then exhausts its budget by purchasing one unit of each security, paying 6 for security A (since the reference price for security A is one) and 12 for security B (since the reference price for security B is 2 ). Because the value purchased is 15 , the auctioneer purchase efficiency is $5 / 6$, slightly lower than 1 but substantially better than in the Grand Auction. As this example illustrates, although the Reference Price Auction does not necessarily eliminate adverse selection, it can help mitigate the problem.

A possible limitation with this basic Reference Price design is that its effectiveness may crucially rely on the ability of the auctioneer to come up with reference prices that reflect the relative security values. In particular, bidders might be able to exploit mispriced reference prices. To illustrate this possibility, consider the example in Table 1 and imagine that the auctioneer "overprices" security B by setting its reference price at three instead of two (its actual relative value). The bidder who owns security B then possesses an advantage compared to the owner of the correctly priced security A. Indeed, all else equal, the normalized bid on security B will be lower (as it is incorrectly scored against a higher reference price), which makes it more likely to be accepted in the auction. As a result, bidders may find it advantageous to exploit overpriced reference prices by submitting higher bids on those securities.

In our example, bidder 2 can take advantage of the fact that security B is overpriced to make sure he sells one unit of security B at a high price. As shown in the bottom panel of Table 1, if bidder 2 increases his bid to 15 on the first unit of security B and keeps his bid at 12 on the second unit, then the market clearing normalized price is 5 . In that case, the auctioneer can only purchase the second unit of security $\mathrm{B}$ (with a normalized bid of $4=12 / 3$ ) at a price of $15=3 \times 5$. As shown in Table 1, bidder 2 now makes a profit of five and the auctioneer's purchase efficiency drops to $2 / 3$ compared to 5/6 when reference prices are accurate.

It is interesting to point out some of the differences with the Grand Auction in this example. In particular, the auctioneer in the Grand Auction purchases the lowest quality security and overpays because of its inability to discriminate between the values of securities A and B. In the Reference Price Auction, with overpriced reference prices, the auctioneer also overpays but purchases a unit of the high quality security. The latter result is not due to the standard form of adverse selection as in the Grand Auction. Instead, it is driven by the errors made by the auctioneer when setting the reference prices. In our example, note also that the purchase efficiency is higher in the Reference Price auction with inaccurate reference prices than in the Grand 
Auction. Intuitively, this result should depend on the relative strength of two effects: the extent of adverse selection in the Grand Auction versus the extent of mispricing in the Reference Price Auction. Finally, observe that the Grand Auction is a special case of the Reference Price Auction in which all the reference prices are incorrectly set to one. In our Grand Auction example in the top panel of Table 1, security B (with a relative value of two) is therefore underpriced. Because of this relative advantage, security A is purchased by the auctioneer at a price that exceeds its value.

Several measures were proposed to mitigate the problem of incorrect reference prices. In particular, it was suggested that keeping reference prices secret at the time of the auction would prevent the bidders from exploiting mispriced securities. To illustrate, consider the example in Table 1 and imagine the auctioneer does not reveal ex ante the reference price for security B. Assume also that, consistent with the previous examples, the auctioneer's reference price for security B can be either (i) inaccurate and underpriced (i.e., equal to one) with probability $1 / 4$, (ii) accurate (i.e., equal to two) with probability $1 / 2$, or (iii) inaccurate and overpriced (i.e., equal to 3 ) with probability $1 / 4$. In that case, it can be verified that it is an equilibrium for bidder 1 to bid 5 on security $\mathrm{A}$ and for bidder 2 to bid 12 on each unit of security B. ${ }^{10}$ In that case, the auctioneer's expected purchase efficiency is $35 / 48$ (or about 0.73 ), which is higher than $1 / 2$ and $2 / 3$, the purchase efficiencies when it is known before the auction that security $\mathrm{B}$ is respectively underpriced and overpriced (see the top and bottom panels of Table 1). Thus, in this example, keeping reference prices secret provides some protection to the auctioneer against mispriced reference prices. ${ }^{11}$ However, one should question whether the results from a simple complete information example extend to more general environments. To explore this issue, we report in the next section on an experiment conducted with real bidders and incomplete information.

\section{Experimental Procedures}

The experiment consists of four treatments. As explained below, these treatments essentially differ in two ways: the accuracy of the reference prices and whether the reference prices are announced before or after the auction. For each treatment, we conducted six sessions in which six subjects competed in eight successive auctions. The sessions, which lasted about an hour and fifteen minutes, were conducted

\footnotetext{
${ }^{10}$ The expected profits of bidders 1 and 2 given this pair of strategies are $9 / 4$ and 6/4, respectively. Since bidder 1 systematically bids five in equilibrium whether or not the reference prices are accurate (see the three panels in Table 1), it is easy to verify that he has no incentives to deviate. Likewise, if bidder 2 deviates and increases the bid on the first unit to 15 (as in the lower panel of Table 1), then his expected profits drop to 5/4.

${ }^{11}$ Revealing reference prices only after the auction raises a commitment concern since the auctioneer may have an incentive to revise its reference prices based on the information contained in the bids submitted. In fact, one aspect of the proposal by Goeree and Holt (2008) for the TARP involved endogenized reference prices, i.e., modified ex-post as a result of the bids submitted. An additional feature suggested by Plott (2008) to help banks fill possible needs for liquidity targets was to allow bidders to submit a small number of "conditional package bids," i.e., a bundle of individual bids, accompanied with the condition "if one bid in the package is accepted, then all other bids in the package are cancelled."
} 
with undergraduate students in the Veconlab at the University of Virginia and at the CIRANO's Bell Laboratory for Experimental Economics in Montréal. ${ }^{12}$

Each auction involved six securities, labeled A through F. Each security was divided in ten shares, and each bidder was endowed with five shares of one security, three of a second, and two of a third. The ownership pattern was balanced in the sense that each security was distributed across three subjects who owned five, three, and two shares, respectively. This ownership concentration was intended to provide more opportunities for strategic bidding and more of a stress test of the auction designs.

Given the complex nature of the environment and the relatively unfamiliar procurement (low bids win) auction format, we decided to include some context, without being too specific. ${ }^{13}$ For example, the items being purchased were referred to as "shares" of "securities" instead of "mortgage-backed securities," and the buyer was referred to as the "government" instead of the "Treasury." This terminology will be used in the discussion of the experimental results.

As explained in the previous section, we consider the sealed bid, uniform-price auction with reference prices the Treasury was considering to implement. Prior to each auction, each of the securities was assigned a common value that was randomly drawn from a uniform distribution on a range $[20,80]$. Each subject received three private signals, one for each security she/he owned, each independently drawn from a uniform distribution centered at the true security value, with a range of plus or minus ten. Since the true values were between 20 and 80 , the possible signals spanned the range from 10 to $90 .{ }^{14}$ Bidders were told to think of these numbers as "dollars per hundred of par value." In some of the treatments, the government also received noisy signals about the securities' values through random numbers drawn from a uniform distribution with a range of plus or minus 20 from the true value of the security. Thus the government received lower quality information than the bidders, as its signals were twice as noisy.

Note, also, that we used matching sets of random draws for each treatment (akin to a common random number technique), i.e., each treatment was conducted with the same series of six random number seed values (one per session). Therefore, all sets of random draws (for the security values, the bidders' value signals and, when relevant, the government's value signals) were the same across treatments for each of the 48 auctions in a treatment. As a result, the experimental outcomes obtained in each treatment may be compared directly.

\footnotetext{
${ }^{12}$ It is common to conduct lab experiments with students to test the properties of new mechanisms (see the examples in footnote 3). Such "wind tunnel" experiments have proved very informative about the actual behavior of professionals when the mechanism is ultimately implemented in the field. Note also that the Veconlab Reverse Auction program used for the experiment is listed under the Auctions menu at http://veconlab.econ.virginia.edu/ admin.php. A copy of the instructions is provided in the supplemental materials.

${ }^{13} \mathrm{We}$ recognize that there are pros and cons in introducing some context when describing the experiment to the subjects. Note, however, that the terminology used was the same across treatments. Moreover, we did not observe any obvious differences in behavior in the sessions conducted in the United States (Virginia) and in Canada (Montréal), where no bailout took place.

${ }^{14} \mathrm{~A}$ feature of this type of common value auction is that extreme signals are more informative. In particular, signals below 30 and above 70 restrict the range of possible true values. In our experiment, 21 percent of the signals are below 30 or above 70 . As explained later on, the same signals were used in all treatments, so that the comparison across treatments is valid.
} 
The government purchase budget was set at 2,000 (experiment dollars), corresponding to two-thirds of the expected value of the 60 shares for sale at an auction $(3,000)$. This ratio is relatively high compared to what the Treasury was actually considering for the TARP auction (i.e., no more than 50 percent of the total value of the securities included in the auction). We chose such a high budget to help subjects earn money by selling at high prices.

Bidders could submit "supply functions," i.e., they could enter a bid price for each share of each security they own. At the time subjects submit their bids, the following information is common knowledge: (i) the government purchase budget, (ii) the distribution of security endowments across bidders, (iii) the distribution from which the security values are randomly drawn, (iv) the conditional distributions of the bidders' signals, and (v) in the relevant treatments, the conditional distributions of the government's signals.

For each accepted bid, the bidder earns the difference between the price received from the government and the true value of the security. Otherwise, earnings are zero. It follows that each auction is a zero-sum game, so government losses are equal to the bidders' profits. ${ }^{15}$ The cash payout rate was $\$ 0.05$ per experiment dollar, and they were generally in the \$13-\$30 range, with an average of \$23.

The four treatments are summarized in Table 2. These treatments were designed to address the most important concerns raised by the Treasury team: How much of an improvement would a Reference Price Auction be compared to a Grand Auction? How sensitive is a Reference Price Auction to noisy reference prices? Does purchase efficiency improve when noisy reference prices are kept secret?

Treatment 1: Grand Auction.-Bids for all securities are collected, ranked and the government purchases the securities with the lowest price until its budget is exhausted. The price of the lowest rejected bid determines the market clearing price. A bidder is paid the market clearing price for each share of a security accepted by the government. This implies that all securities are purchased by the government at the same price regardless of type.

The main object of this treatment is to serve as a lower benchmark against which the treatments involving reference prices will be compared. Indeed, as discussed in Section I, this simple combined auction should yield low purchase efficiency because of adverse selection.

Treatment 2: Announced Accurate Reference Price Auction.-This treatment is the same as Treatment 1, except that the government divides bids for a security by a reference price announced to bidders before the auction. Each reference price in this treatment is perfectly accurate, i.e., equal to the ratio of a security's value to the value of the baseline security A. As explained in the previous section, the government purchases the securities with the lowest normalized prices. The normalized price of the lowest rejected bid gives the normalized market clearing

\footnotetext{
${ }^{15}$ In practice, this may not have been the case for the TARP auction. Indeed, some have argued that the securities were worth less to the bidders than to the government because (i) the government may have been a more patient investor, or (ii) some bidders faced a need for immediate liquidity.
} 
Table 2-Treatments and Associated Reference Price Structures

\begin{tabular}{lcc}
\hline \hline Treatment & $\begin{array}{c}\text { Reference price } \\
\text { estimates }\end{array}$ & $\begin{array}{c}\text { Reference price } \\
\text { information }\end{array}$ \\
\hline $\begin{array}{l}\text { Grand Auction (no reference prices) } \\
\text { Announced accurate reference prices }\end{array}$ & None & Irrelevant \\
Announced noisy reference prices & Accurate & Announced \\
Secret noisy reference prices & Noisy & Announced \\
Secret
\end{tabular}

price, which is determined recursively so as to exhaust the auction budget. The actual price paid by the government for a security is then determined by multiplying the reference price for that security by the common normalized market clearing price.

In this ideal case where relative security values are precisely known by the government, the reference prices should create a level playing field by homogenizing the bids for securities of different values, and should therefore promote competition across bidders and securities. Again, we only consider this extreme scenario to provide an upper bound on purchase efficiency to which the other two treatments with noisy reference prices will be compared.

Treatment 3: Announced Noisy Reference Price Auction.-This treatment is the same as Treatment 2, except that the government now relies on noisy reference prices determined as ratios of the government's noisy signal for each security to the government's noisy signal for the base security A.

This treatment may be considered an extreme case of an auction with noisy reference prices for at least two reasons. First, because its signals are twice as noisy as the bidders', the government's information about the absolute value of each security is quite poor. Second, the government's information about the relative values of the securities is even poorer. Indeed, by taking the ratio of its noisy signals the government compounds its errors. As a result, the reference prices the government uses to decide which security to purchase may be highly inaccurate, or even close to meaningless in some cases. In our experiment, for instance, the reference price for one of the securities in one of the eight auctions was incorrectly set at one-ninth of its actual relative value.

As explained in Section I, bidders may be able to take advantage of "overpriced" reference prices when noisy reference prices are announced before the auction. Thus, compared to the previous treatment with accurate reference prices, one may expect the government to pay more to acquire the same value.

Treatment 4: Secret Noisy Reference Price Auction.-This treatment is the same as Treatment 3 except that the government does not announce its noisy reference prices before the auction. In other words, in each of the eight auctions, the government receives the same set of signals and therefore sets the same noisy reference prices as in Treatment 3. Likewise, the allocation mechanism and the pricing rules are exactly the same as in Treatment 3 . The only difference with Treatment 3 is that bidders must now form expectations about the reference prices the government will use to score their bids. 
TABle 3-Auction Outcomes By TREATMEnt

Averages and standard deviations (in parentheses) are calculated over the eight auctions in each treatment

\begin{tabular}{llcccc}
\hline \hline Row & & $\begin{array}{c}\text { Treatment 1 } \\
\text { Grand Auction } \\
\text { no reference } \\
\text { prices }\end{array}$ & $\begin{array}{c}\text { Treatment } 2 \\
\text { Accurate } \\
\text { announced } \\
\text { reference prices }\end{array}$ & $\begin{array}{c}\text { Treatment 3 } \\
\text { Noisy } \\
\text { announced } \\
\text { reference prices }\end{array}$ & $\begin{array}{c}\text { Treatment 4 } \\
\text { Noisy } \\
\text { secret } \\
\text { reference prices }\end{array}$ \\
\hline 1 & Government & $1,912.4$ & $1,955.0$ & $1,934.9$ & $1,943.2$ \\
expenditure & $(103.6)$ & $(48.0)$ & $(38.8)$ & $(52.8)$ \\
& Value of securities & $1,465.1$ & $1,830.2$ & $1,694.2$ & $1,659.5$ \\
purchased & $(207.1)$ & $(177.5)$ & $(208.5)$ & $(142.6)$ \\
& Purchase & 0.766 & 0.936 & 0.876 & 0.854 \\
efficiency & $(0.106)$ & $(0.087)$ & $(0.102)$ & $(0.068)$ \\
\hline
\end{tabular}

${ }^{\dagger}$ Purchase efficiency is defined as the ratio of the value purchased to the government expenditure.

By not announcing reference prices before the auction, the government should be protected against strategic reactions to overpriced reference prices, and hence, the purchase efficiency should be higher with secret noisy reference prices than with announced noisy reference prices.

\section{Laboratory Results}

Summary outcome measures are organized by treatment in Table 3. As is apparent in row 1, the government nearly exhausts its $\$ 2,000$ auction purchase budget in all treatments. Row 2 in Table 3 gives the total value of the securities purchased by the government (on average) in each auction. Observe that the government operates the auctions at a loss in our experiment since its expenditure (row 1) exceeds the total value of the securities purchased (row 2) for all four treatments. Since this is a zero-sum game, subjects earn positive profits in all treatments. This result is not surprising given the relatively high budget we set for the government to guarantee our subjects positive earnings.

The best way to appreciate differences across treatments is to consider the purchase efficiency in row 3. The Grand Auction produced an efficiency ratio of 0.766 , meaning that for every dollar spent, the government purchases only 76.6 cents in value. In contrast, the accurate announced Reference Prices Auction is almost fully efficient, with an efficiency percentage of nearly 94 percent. In other words, if the government has precise estimates of the securities' relative values, then, as hypothesized, a Reference Price Auction homogenizes the different securities and produces a nearly efficient outcome. The outcomes of both the Grand Auction and the accurate announced Reference Price Auction are therefore consistent with our predictions, as the two treatments constitute two opposite benchmarks.

As indicated in the last two columns of Table 3 (row 3), the two treatments with noisy reference prices produce intermediate results. More specifically, the purchase efficiency ratios are 0.876 and 0.854 when the reference prices are respectively announced or kept secret before the auction. This implies that a Reference Price Auction is superior to the Grand Auction even when the government has little information about the relative values of the securities. Observe, however, that keeping the noisy reference prices secret at the time of the auction does not improve the 


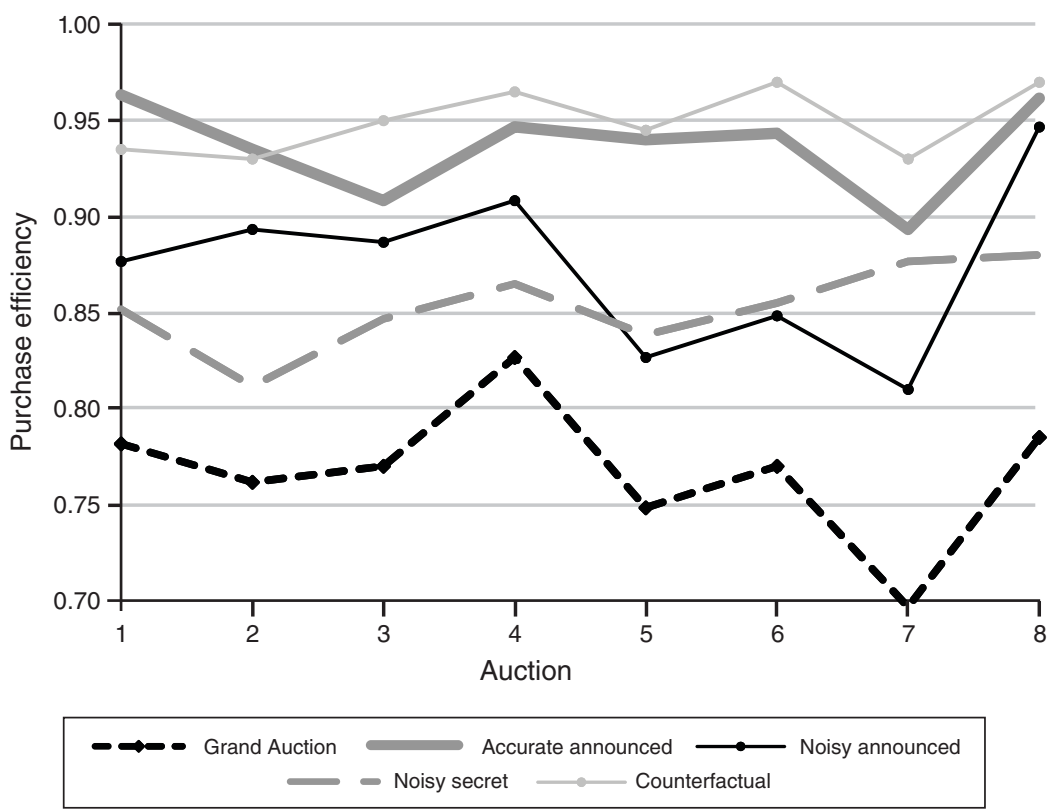

Figure 1. Purchase Efficiency by Auction

Note: Value purchased to expenditure ratio averaged over the six sessions.

auction efficiency, in contrast with our prediction. Below, we show that this result is not due to the fact that the auction with secret noisy reference prices underperformed. Instead, we find evidence that the auction with announced noisy reference prices performed beyond expectations because it created competitive incentives that offset incentives to exploit mispriced reference prices. To sum up, the Reference Price Auctions clearly dominate the Grand Auction even when reference prices are extremely noisy, but keeping reference prices secret before the auction does not increase purchase efficiency.

These differences between treatments also hold up on an auction-by-auction basis, as shown in Figure 1 where we plot the efficiency ratio averaged over the six sessions in each of the eight auctions conducted. (Please ignore the "counterfactual" line, which will be explained below.) The Grand Auction is always the least efficient, while the auction with accurate announced reference prices is systematically the most efficient. The two treatments with noisy reference prices produce intermediate and somewhat similar efficiency ratios. Another interesting feature of the figure is that the purchase efficiency measures are fairly flat, thereby showing no evidence of learning or strategic adjustments (except for a possible decline in performance across auctions in the Grand Auction, which will be evaluated below). In other words, the dominance of the Reference Price Auction in terms of efficiency is immediate and does not require the bidders to familiarize themselves with the slightly more complex auction design.

Compared to the benchmark auction with accurate reference prices, the drop in efficiency in the two noisy reference price treatments may be the result of both 
Table 4-Purchase Efficiency by Session

Value purchased to expenditure ratios averaged over all eight auctions per session

\begin{tabular}{lcccc}
\hline \hline Row & $\begin{array}{c}\text { Treatment: } \\
\text { reference prices }\end{array}$ & $\begin{array}{c}\text { Session purchase efficiency } \\
\text { averages for seeds 1 to 6 }\end{array}$ & $\begin{array}{c}\text { Treatment } \\
\text { average }\end{array}$ & $\begin{array}{c}\text { Wilcoxon } \\
\text { signed-rank test }^{\text {a }}\end{array}$ \\
\hline 1 & Grand Auction (none) & $0.79,0.81,0.79,0.77,0.72,0.74$ & 0.766 & \\
2 & Announced, noisy & $0.85,0.86,0.89,0.92,0.90,0.83$ & 0.876 & $\begin{array}{c}Z=-2.201 \\
p \text {-value }=0.028\end{array}$ \\
3 & Secret, noisy & $0.84,0.84,0.87,0.83,0.87,0.87$ & 0.854 & $\begin{array}{c}Z=1.166 \\
p \text {-value }=0.244 \\
Z=-2.207\end{array}$ \\
4 & Announced, accurate & $0.91,0.91,0.97,0.89,0.99,0.95$ & 0.936 & $\begin{array}{c}Z \\
p \text {-value }=0.027\end{array}$ \\
& & & &
\end{tabular}

${ }^{\text {a }}$ Each test compares the distribution of the six ratios in the corresponding row with the distribution of the six ratios in the row above.

(i) incorrect reference prices, and (ii) bidders strategically adjusting their behavior in response to mispriced reference prices. In an effort to disentangle these two effects, we conduct a counterfactual exercise. The question raised in this exercise is: What would the purchase efficiency be in Treatment 4 if the bids submitted had been scored against accurate instead of noisy reference prices? To address this question, we take the bids the subjects submitted in Treatment 4 and score them against accurate reference prices. ${ }^{16}$ As indicated in Figure 1, the purchase efficiency ratios in the counterfactual exercise are systematically higher than those in the two noisy reference price treatments, and similar to those observed when reference prices are accurate and announced (Treatment 2). This result suggests that the lower purchase efficiency ratios in the two noisy reference price treatments may be attributed primarily to noisy reference prices, not to adverse selection (as in the Grand Auction), nor strategic bidding adjustments in the face of greater uncertainty about reference prices.

To test statistically for treatment effects, we compare the purchased efficiency averaged over the eight auctions conducted for the six sessions in each treatment. These statistics are independent (since subjects could participate in one session only) and directly comparable (since the six sessions in each treatment were conducted with the same six random seed values). The session averages, arranged by seed, are shown in Table 4. For all six seed values, the average purchase efficiency ratios are lowest for the Grand Auction (row 1) and highest for the auction with accurate announced reference prices (row 4). These differences are significant at conventional levels, using Wilcoxon signed-rank tests, as shown in the last column of the table. Finally, we find no significant difference between the two noisy reference prices treatments ( $p=0.24$ for a 2-tailed test), despite the fact that the average efficiency ratios are higher for five out of six seeds when the noisy reference prices are announced (row 2) rather than kept secret (row 3).

\footnotetext{
${ }^{16}$ The key assumption underlying the counterfactual exercise is that subjects in Treatment 4 would have behaved in the same way had the secret reference prices been accurate instead of noisy.
} 


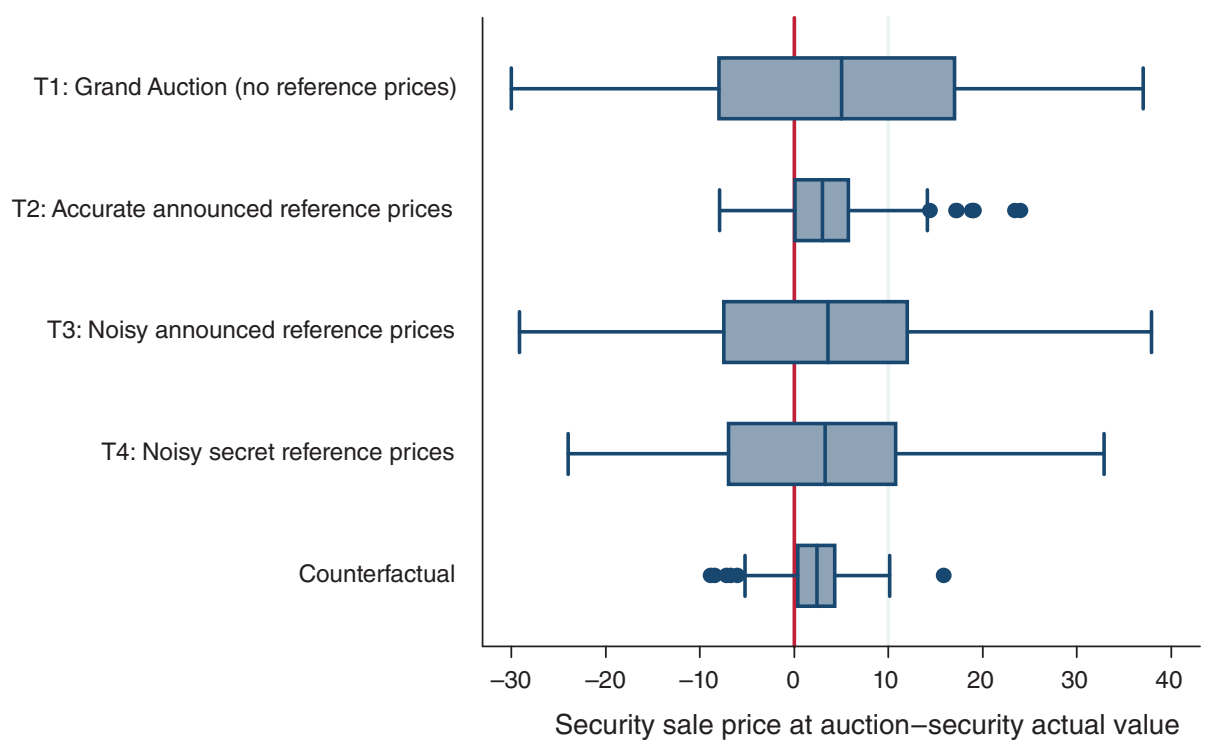

Figure 2. Distribution of the Difference between the Security Sale Price and the Security Actual Value

Notes: The line inside a box characterizes the median, while the borders of the box characterize the 25th and 75 th percentiles. The ends of the whiskers represent the 5th and 95th percentiles. Finally, the dots represent outliers.

When purchase efficiency is measured in terms of the ratio of value purchased to the government's expenditure, the main results of this section can be summarized:

Purchase Efficiency Results.- Purchase efficiency in the experiment is lowest when reference prices are not used (the Grand Auction) and it is close to full value when reference prices are accurate measures of relative security values. Intermediate efficiency measures are observed when the government only possesses noisy reference prices, but these efficiency measures are not improved by keeping reference prices secret before the auction. The counterfactual exercise suggests that the lower efficiencies in the treatments with noisy reference prices are mostly due to the highly inaccurate reference prices, rather than to bidder strategic responses to noisy reference prices. ${ }^{17}$

Having compared the different auction formats with respect to purchase efficiency, we now consider the issue of price discovery, i.e., the extent to which the auction clearing prices for each security provide accurate information about their unobserved values. As shown in Figure 2, the median clearing price in each treatment is slightly above the underlying security values, thereby reflecting the government's overpayment (or conversely, the subjects' profits) in the auctions.

\footnotetext{
${ }^{17}$ To test the robustness of the results in this section, we conducted additional treatments (reported as supplemental materials) using alternative earnings and reference price procedures. These robustness checks confirm the ranking of the four treatments with respect to purchase efficiency.
} 
With respect to the distribution of auction clearing prices, we can see in Figure 2 that the Grand Auction produces dispersed and essentially uninformative prices. In contrast, the auction clearing prices are tightly distributed when reference prices are accurate (Treatment 2). There are no obvious differences between the two treatments with noisy reference prices: they are both slightly better than the Grand Auction in terms of price discovery, but worse than when reference prices are accurate. These observations can be summarized:

Price Discovery Results. - Auction clearing prices tend to exceed the underlying security values in all treatments, with the greatest dispersion in the Grand Auction and the least dispersion in the accurate Reference Price Auction. Keeping reference prices secret before the auction does not improve price discovery.

To explain the somewhat surprising result that purchase efficiencies and price discovery measures do not improve when reference prices are kept secret, we conduct in the next section an econometric analysis of individual bidding patterns.

\section{Econometric Analysis}

The analysis in this section is based on behavioral patterns that emerge from a series of reduced-form panel regressions of the form:

$$
Y_{i, t, s, k}=\alpha X_{i, t, s, k}+\mu_{i}+\mu_{t}+\mu_{i, t}+U_{i, t, s, k},
$$

where $Y_{i, t, s, k}$ and $X_{i, t, s, k}$ are respectively the endogenous and explanatory variables (to be specified below), the subscript $i=1, \ldots, 36$ indexes subjects in a specific treatment, $t=1, \ldots, 8$ characterizes the auction number, $s=1, \ldots, 6$ is a security for sale at an auction, and $k=1, \ldots, 5$ captures the order (from lowest to highest) of the bids submitted by a bidder for a unit of a given security. So, $k=1$ corresponds to the lowest bid submitted by a subject for a unit of a given security. The error term is $U_{i, t, s, k}, \mu_{i}$ is an individual random effect, $\mu_{t}$ is an auction random effect and $\mu_{i, t}$ is an individual/auction random effect. Finally, $U_{i, t, s, k}, \mu_{i}, \mu_{t}$, and $\mu_{i, t}$ are assumed to be independent, mean zero and normally distributed with $\operatorname{Var}\left(U_{i, t, s, k}\right)=\sigma_{U}^{2}$, $\operatorname{Var}\left(\mu_{i}\right)=\sigma_{i}^{2}, \operatorname{Var}\left(\mu_{t}\right)=\sigma_{t}^{2}$, and $\operatorname{Var}\left(\mu_{i, t}\right)=\sigma_{i, t}^{2} \cdot 18$

\section{A. Bidding Behavior}

Table 5 shows the estimation outcomes for the model in equation (1) when the dependent variable is the price bid by a subject for a unit of a given security. ${ }^{19}$ In all treatments, we find that, all else equal, subjects tend to submit higher bids when they receive a high signal (row 1) and for the last bids they submit for a given security

\footnotetext{
${ }^{18}$ Because the likelihood function cannot be expressed in closed form, the model is estimated by Maximum Simulated Likelihood and the estimates' standard errors are evaluated by bootstrap. The results presented below are virtually identical when we include a session fixed effect.

${ }^{19}$ Estimation results with significant parameters only are provided in the supplemental materials.
} 
Table 5- Econometric Analysis of Price Bid

\begin{tabular}{|c|c|c|c|c|c|}
\hline & & $\begin{array}{c}\text { Grand Auction } \\
\text { no reference prices }\end{array}$ & $\begin{array}{l}\text { Accurate announced } \\
\text { reference prices }\end{array}$ & $\begin{array}{l}\text { Noisy announced } \\
\text { reference prices }\end{array}$ & $\begin{array}{l}\text { Noisy secret } \\
\text { reference prices }\end{array}$ \\
\hline 1 & Signal & $\begin{array}{l}0.907 * * * \\
(0.011)\end{array}$ & $\begin{array}{l}0.824 * * * \\
(0.019)\end{array}$ & $\begin{array}{l}0.737 * * * \\
(0.021)\end{array}$ & $\begin{array}{l}0.850 * * * \\
(0.025)\end{array}$ \\
\hline 2 & Auction number & $\begin{array}{l}0.335^{* * *} \\
(0.078)\end{array}$ & $\begin{array}{l}0.427 * * * \\
(0.109)\end{array}$ & $\begin{array}{c}0.176 \\
(0.145)\end{array}$ & $\begin{array}{l}-0.283^{* * *} * \\
(0.072)\end{array}$ \\
\hline 3 & $\begin{array}{c}\text { Number of } \\
\text { contracts owned }\end{array}$ & $\begin{array}{c}-0.448 * \\
(0.276)\end{array}$ & $\begin{array}{r}-0.198 \\
(0.480)\end{array}$ & $\begin{array}{r}-0.800 \\
(0.573)\end{array}$ & $\begin{array}{r}-0.329 \\
(0.262)\end{array}$ \\
\hline 4 & Bid number & $\begin{array}{l}3.434 * * * \\
(0.571)\end{array}$ & $\begin{array}{l}5.469 * * * \\
(1.033)\end{array}$ & $\begin{array}{l}5.534 * * * \\
(1.296)\end{array}$ & $\begin{array}{l}6.070^{* * * *} \\
(0.584)\end{array}$ \\
\hline 5 & $\begin{array}{c}\text { Bid number } \times \\
\text { number of contracts }\end{array}$ & $\begin{array}{c}-0.315^{* *} \\
(0.124)\end{array}$ & $\begin{array}{c}-0.577 * * \\
(0.214)\end{array}$ & $\begin{array}{c}-0.574 * * \\
(0.222)\end{array}$ & $\begin{array}{l}-0.666^{* * * *} \\
(0.116)\end{array}$ \\
\hline 6 & Reference price & - & $\begin{array}{l}5.826^{* * * *} \\
(0.542)\end{array}$ & $\begin{array}{l}2.340 * * * \\
(0.529)\end{array}$ & $\begin{array}{c}-0.151 \\
(0.245)\end{array}$ \\
\hline 7 & $\begin{array}{l}\text { "Overpriced" } \\
\text { reference price }\end{array}$ & - & - & $\begin{array}{l}1.702 * \\
(0.893)\end{array}$ & $\begin{array}{c}0.847 \\
(0.576)\end{array}$ \\
\hline 8 & $\begin{array}{l}\text { "Underpriced" } \\
\text { reference price }\end{array}$ & - & - & $\begin{array}{l}-6.294 * * * \\
(1.807)\end{array}$ & $\begin{array}{c}-0.191 \\
(0.781)\end{array}$ \\
\hline 9 & Constant & $\begin{array}{l}-2.188 \\
(1.570)\end{array}$ & $\begin{array}{c}-7.336 * * \\
(2.337)\end{array}$ & $\begin{array}{c}3.980 \\
(2.917)\end{array}$ & $\begin{array}{c}1.282 \\
(1.287)\end{array}$ \\
\hline 10 & $\sigma_{U}$ & $\begin{array}{l}5.215^{* * *} \\
(0.421)\end{array}$ & $\begin{array}{l}6.226 * * * \\
(0.688)\end{array}$ & $\begin{array}{l}7.340 * * * \\
(1.097)\end{array}$ & $\begin{array}{l}6.641^{* * * *} \\
(0.720)\end{array}$ \\
\hline 11 & $\sigma_{i}$ & $\begin{array}{l}5.304 * * * \\
(0.126)\end{array}$ & $\begin{array}{l}6.380^{* * * *} \\
(0.218)\end{array}$ & $\begin{array}{l}8.750 * * * \\
(0.246)\end{array}$ & $\begin{array}{l}6.045^{* * * *} \\
(0.132)\end{array}$ \\
\hline 12 & $\sigma_{t}$ & $\begin{array}{l}4.084 * * * \\
(0.132)\end{array}$ & $\begin{array}{l}3.865^{* * * *} \\
(0.183)\end{array}$ & $\begin{array}{l}4.729 * * * \\
(0.193)\end{array}$ & $\begin{array}{l}3.865^{* * * *} \\
(0.134)\end{array}$ \\
\hline 13 & $\sigma_{i, t}$ & $\begin{array}{l}1.326 * * * \\
(0.412)\end{array}$ & $\begin{array}{l}1.872 * * * \\
(0.325)\end{array}$ & $\begin{array}{l}3.816^{* * * *} \\
(0.658)\end{array}$ & $\begin{array}{l}2.705 * * * \\
(0.846)\end{array}$ \\
\hline 14 & log likelihood & $-8,829.7$ & $-11,066.3$ & $-11,398.0$ & $-9,515.2$ \\
\hline
\end{tabular}

Notes: The models are estimated by maximum simulated likelihood. Standard errors are evaluated by bootstrap.

${ }^{\dagger}$ For security $S$, Overpriced (Underpriced) is set equal to $|A| \times I_{A>0}\left(|A| \times I_{A<0}\right)$, where $A$

$=$ Reference Price $_{S}-$ Value $_{S} /$ Value $_{A}$.

*** Significant at the 1 percent level.

** Significant at the 5 percent level.

* Significant at the 10 percent level.

(row 4). These results were expected. In particular, the second result simply reflects the fact that bids are ranked in ascending order.

We also identify different forms of learning across treatments. All else equal, subjects in the Grand Auction tend to submit higher bids from one auction to the next (row 2). Likewise, subjects in Treatment 2 (Accurate Announced Reference Prices) learn to bid less aggressively. ${ }^{20}$ In contrast, subjects in Treatment 4 (Secret Noisy Reference Prices) lower their bids significantly over time. They seem to learn that they must become more aggressive for their bids to be accepted.

In all treatments, subjects tend to send lower bids when they have some market power for that security (i.e., when they own more contracts of that security), but the effect is in general insignificant (row 3). Interacting the bid number and the number

\footnotetext{
${ }^{20}$ Further analysis (not reported here) reveals that subjects in Treatment 2 learn to submit higher bids for highvalue securities (or equivalently, for securities with high reference prices).
} 
of contracts owned yields negative and significant estimates (row 5), indicating that bidders who own more units of a security raise their prices from one unit of that security to the next at a slower pace.

We now turn to the specific influence (i.e., controlling for the bidder's signal) of reference prices on bidding for the last three treatments with reference prices (row 6). When the reference prices are kept secret at the time of the auction (Treatment 4), we find no relationship between the bids submitted and the reference prices, as would be expected. In contrast, bids are positively correlated with announced reference prices, as hypothesized.

We can also evaluate how subjects adjust their bids in Treatments 3 and 4 in response to the errors the government makes when setting reference prices. To do so, we calculate the absolute deviation between the government's noisy reference price ratio and the true ratio of values (i.e., the ratio of the security's true value divided by the true value of security A). The variable "Overpriced Reference Price" (respectively "Underpriced Reference Price") is then set equal to this absolute deviation when the difference between the government's reference price ratio and the true ratio of values is positive (respectively negative).

As expected, neither form of mispricing influences bids in Treatment 4 with secret reference prices (rows 7 and 8) since the bidders are unable to observe the bias in advance. In that respect, keeping reference prices secret does protect the government against incorrect reference prices. In contrast, when noisy reference prices are announced (Treatment 3), we can see that, as expected, subjects take advantage of overpriced reference prices by bidding higher (row 7). The effect, however, is only significant at the 10 percent level, and its magnitude is not significantly greater than in the noisy secret Reference Price Auction.

Interestingly, our results suggest that subjects bid substantially more aggressively in Treatment 3 when the reference price is underpriced (row 8). In other words, it appears that bidders who own a security that has been underpriced realize that they are at a disadvantage, and they try to compensate by lowering their bids to remain competitive. Observing such behavior was somewhat surprising to us, as it not only reflects strategic sophistication on the part of our subjects, but also it was not anticipated when the Treasury team discussed the merits and potential drawbacks of the Reference Price Auction. This also demonstrates how useful lab experiments can be at testing the impact of public policies to be implemented in complex environments. To summarize:

Bidding Responses to Noisy Reference Prices._- Bids are responsive to announced reference prices and to perceived biases in government preannounced reference prices. Namely, subjects increase their bids slightly when reference prices are overpriced, and lower their bids substantially when reference prices are underpriced. These two effects partially offset each other, which explains why keeping the reference prices secret does not improve the auction purchase efficiency. In other words, the unexpected absence of a significant difference between the last two treatments reflects the fact that the noisy announced reference price treatment performed above expectations, not that the noisy secret reference price treatment performed below expectations. 
TABle 6-Econometric Analysis of Bid AcCEPTANCE

\begin{tabular}{|c|c|c|c|c|c|}
\hline & & $\begin{array}{l}\text { Grand Auction } \\
\text { no reference prices }\end{array}$ & $\begin{array}{l}\text { Accurate announced } \\
\text { reference prices }\end{array}$ & $\begin{array}{l}\text { Noisy announced } \\
\text { reference prices }\end{array}$ & $\begin{array}{l}\text { Noisy secret } \\
\text { reference prices }\end{array}$ \\
\hline 1 & Security value & $\begin{array}{l}-0.089 * * * \\
(0.009)\end{array}$ & $\begin{array}{r}-0.004 \\
(0.004)\end{array}$ & $\begin{array}{r}-0.006 \\
(0.004)\end{array}$ & $\begin{array}{c}-0.010^{* *} \\
(0.004)\end{array}$ \\
\hline 2 & $\begin{array}{c}\text { Signal bias } \\
\text { (i.e., signal - value) }\end{array}$ & $\begin{array}{l}-0.082 * * * \\
(0.014)\end{array}$ & $\begin{array}{l}-0.104 * * * \\
(0.010)\end{array}$ & $\begin{array}{l}-0.058 * * * \\
(0.006)\end{array}$ & $\begin{array}{l}-0.066^{* * * *} \\
(0.010)\end{array}$ \\
\hline 3 & Auction number & $\begin{array}{c}0.005 \\
(0.014)\end{array}$ & $\begin{array}{r}-0.001 \\
(0.019)\end{array}$ & $\begin{array}{r}-0.024 \\
(0.015)\end{array}$ & $\begin{array}{c}0.031 \\
(0.016)\end{array}$ \\
\hline 4 & $\begin{array}{c}\text { Number of } \\
\text { contracts owned }\end{array}$ & $\begin{array}{l}0.242 * * * \\
(0.055)\end{array}$ & $\begin{array}{l}0.138 * * * \\
(0.039)\end{array}$ & $\begin{array}{l}0.137 * * * \\
(0.037)\end{array}$ & $\begin{array}{l}0.158^{* * * *} \\
(0.031)\end{array}$ \\
\hline 5 & Bid number & $\begin{array}{l}-0.312 * * * \\
(0.035)\end{array}$ & $\begin{array}{l}-0.266^{* * *} * \\
(0.042)\end{array}$ & $\begin{array}{l}-0.194 * * * \\
(0.021)\end{array}$ & $\begin{array}{l}-0.298 * * * \\
(0.029)\end{array}$ \\
\hline 6 & Reference price & - & $\begin{array}{r}-0.013 \\
(0.134)\end{array}$ & $\begin{array}{r}-0.019 \\
(0.021)\end{array}$ & $\begin{array}{c}0.086 \\
(0.107)\end{array}$ \\
\hline 7 & $\begin{array}{l}\text { "Overpriced" } \\
\text { reference price" }\end{array}$ & - & - & $\begin{array}{l}0.426^{*} \\
(0.204)\end{array}$ & $\begin{array}{l}1.235^{* * * *} \\
(0.212)\end{array}$ \\
\hline 8 & $\begin{array}{l}\text { "Underpriced" } \\
\text { reference price" }\end{array}$ & - & - & $\begin{array}{l}-2.039 * * * \\
(0.273)\end{array}$ & $\begin{array}{l}-3.016^{* * * *} \\
(0.258)\end{array}$ \\
\hline 9 & Constant & $\begin{array}{l}0.536^{* * * *} \\
(0.071)\end{array}$ & $\begin{array}{l}0.684 * * \\
(0.277)\end{array}$ & $\begin{array}{c}0.515 \\
(0.171)\end{array}$ & $\begin{array}{c}0.606^{*} \\
(0.212)\end{array}$ \\
\hline 10 & $\sigma_{U}$ & $\begin{array}{l}0.581 * * * \\
(0.087)\end{array}$ & $\begin{array}{l}0.569 * * * \\
(0.071)\end{array}$ & $\begin{array}{l}0.523 * * * \\
(0.080)\end{array}$ & $\begin{array}{l}0.436 * * * \\
(0.057)\end{array}$ \\
\hline 11 & $\sigma_{i}$ & $\begin{array}{l}0.417 * * * * \\
(0.055)\end{array}$ & $\begin{array}{l}0.512 * * * \\
(0.050)\end{array}$ & $\begin{array}{l}0.486 * * * \\
(0.057)\end{array}$ & $\begin{array}{l}0.461 * * * \\
(0.039)\end{array}$ \\
\hline 12 & $\sigma_{t}$ & $\begin{array}{l}0.241 * * * \\
(0.052)\end{array}$ & $\begin{array}{l}0.193 * * * \\
(0.032)\end{array}$ & $\begin{array}{l}0.197 * * * \\
(0.042)\end{array}$ & $\begin{array}{l}0.275^{* * * *} \\
(0.049)\end{array}$ \\
\hline 14 & log likelihood & -881.2 & $-1,492.3$ & $-1,562.1$ & $-1,401.2$ \\
\hline
\end{tabular}

Notes: The models are estimated by maximum simulated likelihood. Standard errors are evaluated by bootstrap.

${ }^{\dagger}$ For security $S$, Overpriced (Underpriced) is set equal to $|A| \times I_{A>0}\left(|A| \times I_{A<0}\right)$, where $A$ $=$ Reference Price $_{S}-$ Value $_{S} /$ Value $_{A}$.

*** Significant at the 1 percent level.

** Significant at the 5 percent level.

* Significant at the 10 percent level.

\section{B. Purchase Probabilities}

Next we turn to selection issues, i.e., which securities tend to be purchased in the auctions. We consider a probit panel regression with a latent variable model of the form (1). The dependent variable is equal to one if a bid for a unit of a security is accepted, and zero otherwise. As indicated in Table 6, a bid is more likely to be accepted in each treatment (i) when the bidder's private signal is below the security value (row 2), (ii) when the bidder owns more units of a security (row 4), and (iii) for the first bids submitted for a given security, as these correspond (by construction) to lower bids (row 5). These results are consistent with intuition.

As expected, lower value securities are significantly more likely to be purchased in the Grand Auction (row 1). Although the magnitude is significantly lower, the same effect is found with secret noisy reference prices (Treatment 4). In contrast, the value of a security has no bearing on its probability of being purchased for 
Treatments 2 and 3 in which reference prices are announced in advance. In other words, the use of reference prices appears to be effective in homogenizing securities of different values, but it is not fully effective when reference prices are only announced ex post.

In all treatments with reference prices (Treatments 2, 3, and 4), the probability of a security being purchased is (all else equal) unrelated to its reference price (row 6). In both treatments with noisy reference prices, however, a bid is more likely to be accepted when a reference price is overpriced (row 7) and less likely to be accepted when it is underpriced (row 8). When the reference prices are kept secret (Treatment 4), this result only reflects the mechanics of the allocation process. Indeed, since behavior is the same regardless of the reference pricing errors, bids are automatically more likely to be accepted when a reference price is overpriced. When noisy reference prices are announced in advance, we saw from the estimated bid functions in Table 5 that bidders do indeed adjust their bids in reaction to biases in reference prices. The results obtained in Table 6 for Treatment 3 therefore reflect both a mechanical and a strategic effect. In particular, observe in rows 7 and 8 that the magnitude of the effects of the two forms of mispricing is significantly lower when reference prices are announced in advance (Treatment 3 ) instead of being kept secret (Treatment 4). ${ }^{21}$ Perhaps surprisingly, having noisy reference prices has a greater influence on which securities are purchased when reference prices are secret.

Purchase Probability Results. - In the Grand Auction, the government tends to purchase securities of low value. When reference prices are announced, the purchase probabilities are largely uncorrelated with security values. When reference prices are noisy, announcing them before the auction helps soften (but not increase as hypothesized) the impact of mispricing on the values of securities that are purchased.

\section{Government Losses on Securities Purchased}

Finally, we examine the characteristics of the securities on which the government loses money. To do so, we estimate panel regressions of the form (1) in which the dependent variable is the government losses on each accepted bid, i.e., the security's actual value minus the security's purchased price. ${ }^{22}$

It is apparent from the estimates reported in Table 7 that, in all treatments, the government loses more money (i) on low-value securities (row 1), (ii) when the bidder overestimates the security's value (row 2), and (iii) on the last bids submitted by a bidder for a given security (row 5). In particular, observe in row 2

\footnotetext{
${ }^{21}$ All else equal, incorrectly setting a security's reference price at 1.5 (respectively 0.5 ) instead of 1 increases (respectively reduces) the security's chances of being purchased in the noisy announced reference price treatment by 10 percent (respectively 30 percent). When reference prices are not announced, the analogous increase and decrease percentages are larger, at 25 percent and 51 percent.

${ }^{22}$ The government losses are closely related to the purchase efficiency measures discussed earlier. Indeed, since this is a zero-sum game, the government loses money at an auction when the purchase efficiency is below one. In what follows, our focus is the government losses on a security-by-security basis, not at the auction level.
} 
TABle 7- Econometric Analysis of Government Losses

\begin{tabular}{|c|c|c|c|c|c|}
\hline & & $\begin{array}{c}\text { Grand Auction } \\
\text { no reference prices }\end{array}$ & $\begin{array}{l}\text { Accurate announced } \\
\text { reference prices }\end{array}$ & $\begin{array}{l}\text { Noisy announced } \\
\text { reference prices }\end{array}$ & $\begin{array}{l}\text { Noisy secret } \\
\text { reference prices }\end{array}$ \\
\hline 1 & Security value & $\begin{array}{l}0.892 * * * \\
(0.022)\end{array}$ & $\begin{array}{l}0.153^{* * * *} \\
(0.017)\end{array}$ & $\begin{array}{l}0.208 * * * \\
(0.040)\end{array}$ & $\begin{array}{l}0.157 * * * \\
(0.032)\end{array}$ \\
\hline 2 & $\begin{array}{c}\text { Signal bias } \\
\text { (i.e., signal - value) }\end{array}$ & $\begin{array}{c}-0.073 * * \\
(0.028)\end{array}$ & $\begin{array}{l}-0.134 * * * \\
(0.030)\end{array}$ & $\begin{array}{l}-0.213 * * * \\
(0.064)\end{array}$ & $\begin{array}{c}-0.236 * * * \\
(0.045)\end{array}$ \\
\hline 3 & Auction number & $\begin{array}{c}-0.275^{* *} \\
(0.119)\end{array}$ & $\begin{array}{c}0.163 \\
(0.096)\end{array}$ & $\begin{array}{c}0.262 \\
(0.296)\end{array}$ & $\begin{array}{c}0.171 \\
(0.194)\end{array}$ \\
\hline 4 & $\begin{array}{c}\text { Number of } \\
\text { contracts owned }\end{array}$ & $\begin{array}{c}0.113 \\
(0.088)\end{array}$ & $\begin{array}{l}0.153 * * \\
(0.069)\end{array}$ & $\begin{array}{c}0.003 \\
(0.179)\end{array}$ & $\begin{array}{c}0.395 \\
(0.279)\end{array}$ \\
\hline 5 & Bid number & $\begin{array}{l}-0.109 * * \\
(0.031)\end{array}$ & $\begin{array}{r}-0.070 \\
(0.055)\end{array}$ & $\begin{array}{l}-0.187 * * \\
(0.078)\end{array}$ & $\begin{array}{r}-0.246^{*} \\
(0.127)\end{array}$ \\
\hline 6 & Reference price & - & $\begin{array}{l}-6.824 * * * \\
(0.446)\end{array}$ & $\begin{array}{l}-4.219 * * * \\
(0.768)\end{array}$ & $\begin{array}{r}-0.486 \\
(0.600)\end{array}$ \\
\hline 7 & $\begin{array}{l}\text { "Overpriced" } \\
\text { reference price }\end{array}$ & - & - & $\begin{array}{l}-4.677 * * * \\
(1.226)\end{array}$ & $\begin{array}{l}-2.780 * * * \\
(1.511)\end{array}$ \\
\hline 8 & $\begin{array}{l}\text { "Underpriced" } \\
\text { reference price }\end{array}$ & - & - & $\begin{array}{l}32.435 * * * \\
(3.299)\end{array}$ & $\begin{array}{l}31.743 * * * \\
(3.452)\end{array}$ \\
\hline 9 & Constant & $\begin{array}{c}-39.158 * * * \\
(1.428)\end{array}$ & $\begin{array}{r}-0.509 \\
(0.922)\end{array}$ & $\begin{array}{l}-9.902 * * * \\
(1.867)\end{array}$ & $\begin{array}{l}-12.201 * * * \\
(1.367)\end{array}$ \\
\hline 10 & $\sigma_{U}$ & $\begin{array}{l}2.150 * * * \\
(0.086)\end{array}$ & $\begin{array}{l}1.200 * * * \\
(0.153)\end{array}$ & $\begin{array}{l}2.840 * * * \\
(0.228)\end{array}$ & $\begin{array}{l}1.823^{* * * *} \\
(0.306)\end{array}$ \\
\hline 11 & $\sigma_{i}$ & $\begin{array}{l}2.048 * * * \\
(0.174)\end{array}$ & $\begin{array}{l}1.823^{* * * *} \\
(0.241)\end{array}$ & $\begin{array}{l}6.775 * * * \\
(0.336)\end{array}$ & $\begin{array}{l}5.822 * * * \\
(0.351)\end{array}$ \\
\hline 12 & $\sigma_{t}$ & $\begin{array}{l}1.589 * * * \\
(0.208)\end{array}$ & $\begin{array}{l}1.317 * * * \\
(0.187)\end{array}$ & $\begin{array}{l}1.826 * * * \\
(0.240)\end{array}$ & $\begin{array}{l}1.925 * * * \\
(0.240)\end{array}$ \\
\hline 14 & $\sigma_{i, t}$ & $\begin{array}{l}0.889 * * * \\
(0.276)\end{array}$ & $\begin{array}{l}0.831 * * * \\
(0.275)\end{array}$ & $\begin{array}{l}1.166^{* * * *} \\
(0.285)\end{array}$ & $\begin{array}{l}0.962 * * * \\
(0.343)\end{array}$ \\
\hline 15 & log likelihood & $-4,589.0$ & $-4,492.3$ & $-5,571.0$ & $-5,418.4$ \\
\hline
\end{tabular}

Notes: The models are estimated by maximum simulated likelihood. Standard errors are evaluated by bootstrap.

${ }^{\dagger}$ For security $S$, Overpriced (Underpriced) is set equal to $|A| \times I A>0 \quad(|A| \times I A<0)$, where $A$

$=$ Reference PriceS - ValueS/ValueA.

*** Significant at the 1 percent level.

** Significant at the 5 percent level.

* Significant at the 10 percent level.

that, as expected, the extent of the first effect is significantly larger in the Grand Auction where bidders are more likely to sell low-value securities. Note also that government losses in the Grand Auction tend to increase from one auction to the next (row 3). This result is a direct consequence of the increase in the submitted bids observed previously in Table 5.

Next, consider the effects of using reference prices. When reference prices are announced (Treatments 2 and 3), the government's losses increase with the reference price (row 6), holding constant other factors such as the value of the security. This observation reflects the fact that subjects tend to bid higher in this situation. Finally, as one would expect, the government loses more when reference prices are overpriced (row 7 ) and less when reference prices are underpriced (row 8). Note that, although the magnitudes of both of these effects are larger in Treatment 3 than in Treatment 4 (i.e., when noisy reference prices are announced 
rather than kept secret), the difference between the treatments is not significant. To sum up:

Government Loss Results. - In the Grand Auction, the government loses money on low-value securities it purchases. As predicted, this is much less the case in all three Reference Price Auctions. The impact of incorrectly set reference prices on the government's losses is not significantly affected by whether or not these noisy reference prices are announced or kept secret before the auction.

\section{Conclusion}

The Reference Price Auction the Treasury had chosen to purchase illiquid mortgage-backed securities performed well in our experiment. In particular, it systematically outperformed a Grand Auction even when the reference prices were set with considerable noise and announced before the auction. In other words, we find that, by homogenizing bids for items of different values, a Reference Price Auction can effectively promote competition and mitigate adverse selection. Beyond the TARP auction, these results are relevant to the various multi-object auctions cited in the introduction in which value heterogeneity and informational asymmetries often pose serious efficiency challenges.

These findings illustrate how experimental economics may be a useful complement to economic theory when designing public policy in complex environments or under considerable time pressure. In particular, although the economists and auction designers involved in the project correctly predicted the negative impact of announced overpriced reference prices, they did not anticipate the counterbalancing effect generated by owners of securities with underpriced reference prices. In other words, the experiment revealed that a design with noisy announced reference prices would perform better than expected.

More generally, our results provide some support to the auction designers (e.g., Klemperer 2002) who have argued that beyond optimality considerations, the performance of an auction is mostly driven in practice by basic economics forces. In this case, the relative success of the Reference Price Auction may be explained in large part by the fact that it promotes competition by letting owners of different securities bid against each other on a relatively leveled playing field.

\section{REFERENCES}

Armantier, Olivier. 1999. "Three Essays on the Empirical Application of Game Theoretic Models." PhD diss. University of Pittsburgh.

Armantier, Olivier, Jean-Pierre Florens, and Jean-Françios Richard. 1998. "Équilibre approximatif et règle intuitive: une application aux appels d'offres dans l'industrie spatiale." Economie et Prevision 132 (1): 179-90.

Armantier, Olivier, Charles A. Holt, and Charles R. Plott. 2013. "A Procurement Auction for Toxic Assets with Asymmetric Information: Dataset." American Economic Journal: Microeconomics. http://dx.doi.org/10.1257/mic.5.4.142.

Asker, John, and Estelle Cantillon. 2008. "Properties of scoring auctions." RAND Journal of Economics 39 (1): 69-85.

Ausubel, Lawrence M., and Peter Cramton. 2008. "Auction Design Critical for Rescue Plan.” Economists' Voice 5 (5): Article 5. 
Binmore, Ken, and Paul Klemperer. 2002. "The Biggest Auction Ever: The Sale of the British 3G Telecom Licenses." Economic Journal 112 (478): C74-96.

Brusco, Sandro. 2008. "What is a reverse auction?" Vox, October 21. http://www.voxeu.org/article/ paulson-plan-what-reverse-auction.

- Cason, Timothy N., Lata Gangadharan, and Charlotte Duke. 2003. "A laboratory study of auctions for reducing non-point source pollution." Journal of Environmental Economics and Management 46 (3): 446-71.

-Cummings, Ronald G., Charles A. Holt, and Susan K. Laury. 2004. "Using laboratory experiments for policy making: An example from the Georgia irrigation reduction auction." Journal of Policy Analysis and Management 23 (2): 341-63.

Goeree, Jacob K., and Charlie A. Holt. 2008. "Standardized Uniform-Price Reverse Auctions A MultiMarket Auction Approach for the Treasury's Rescue Plan.” Unpublished.

-Goeree, Jacob K., and Charles A. Holt. 2010. "Hierarchical package bidding: A paper \& pencil combinatorial auction." Games and Economic Behavior 70 (1): 146-69.

Hasbrouck, Joel. 2007. Empirical Market Microstructure. New York: Oxford University Press.

Holt, Charles, William Shobe, Dallas Burtraw, Karen Palmer, and Jacob Goeree. 2008. Auction Design for Selling CO2 Emissions Allowances Under the Regional Greenhouse Gas Initiative. New York State Energy Research Development Authority (NYSERDA). Albany, October.

Holt, Charles A., William M. Shobe, and Angela K. Smith. 2007. "An Experimental Basis for Public Policy Initiatives." In Promoting the General Welfare: New Perspectives on Government Performance, edited by Alan S. Gerber and Eric M. Patashnik, 174-99. Washington, DC: Brookings Institution Press.

Klemperer, Paul. 2002. "What Really Matters in Auction Design.” Journal of Economic Perspectives 16 (1): 169-89.

- Klemperer, Paul. 2010. "The Product-Mix Auction: A New Auction Design for Differentiated Goods." Journal of the European Economic Association 8 (2-3): 526-36.

Plott, Charlie. 2001. Public Economics, Political Processes and Policy Applications: Collected Papers on the Experimental Foundations of Economics and Political Science, Vol. 1. Northampton, MA: Edward Elgar.

Plott, Charlie. 2008. "Proposal for Structuring the Auction of Distressed Mortgage Securities." Unpublished.

Stoneham, Gary, Vivek Chundhri, Arthur Ha, and Loris Strappazzon. 2002. "Victoria's Bush Tender Trial: A Cost Sharing Approach to Biodiversity." Unpublished.

-Swagel, Philip. 2009. "The Financial Crisis: An Inside View." Brookings Paper on Economic Activity 39 (1): 1-63.

Varian, Hal R. 2008. "How to Drink the Sub-Prime Kool-Aid." Economists' Voice 5 (5): Article 13. 